ORP-51803

Revision 0

\title{
Melting of Glass Batch: Model for Multiple Overlapping Gas-Evolving Reactions
}

Prepared for the U.S. Department of Energy

Assistant Secretary for Environmental Management

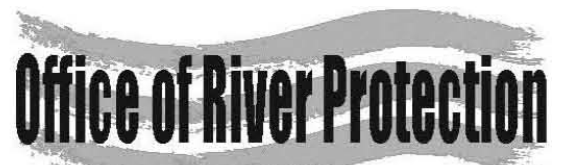

P.O. Box 450

Richland, Washington 99352 
ORP-51803

Revision 0

\section{Melting of Glass Batch: Model for Multiple Overlapping Gas-Evolving Reactions}

\author{
A. A. Kruger \\ Department of Energy - Office of River Protection \\ D. A. Pierce \\ Pacific Northwest National Laboratory
}

\author{
R. Pokorny \\ Institute of Chemical Technology in Prague \\ P. R. Hrma \\ Pacific Northwest National Laboratory
}

Date Published

February 2012

DOE-ORP

Published in

Journal of Thermal Analysis and Calorimetry

Prepared for the U.S. Department of Energy

Assistant Secretary for Environmental Management

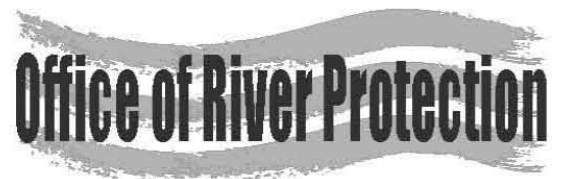

P.O. Box 450

Richland, Washington 99352

Copyright License

By acceptance of this article, the publisher and/or recipient acknowledges the U.S. Government's right to retain a non exclusive, royalty-free license in an to any copyright covering this paper. 
ORP-51803

Revision 0

\section{LEGAL DISCLAIMER}

This report was prepared as an account of work sponsored by an agency of the United States Government. Neither the United States Government nor any agency thereof, nor any of their employees, makes any warranty, express or implied, or assumes any legal liability or responsibility for the accuracy, completeness, or any third party's use or the results of such use of any information, apparatus, product, or process disclosed, or represents that its use would not infringe privately owned rights. Reference herin to any specific commercial product, process, or service by trade name, trademark, manufacturer, or otherwise, does not necessarily constitute or imply its endorsement, recommendation, or favoring by the Unites States

Government or any agency thereof or its contractors or subcontractors. The views and opinions of authors expressed herein do not necessarily state or reflect those of the United States Government or any agency thereof.

This report has been reproduced from the best available copy.

Printed in the United States of America 


\title{
MELTING OF GLASS BATCH: MODEL FOR MULTIPLE OVERLAPPING GAS- EVOLVING REACTIONS
}

\author{
Richard Pokorný, ${ }^{1}$ David A. Pierce, ${ }^{2}$ Pavel Hrma, ${ }^{2,3}$ \\ ${ }^{1}$ Department of Chemical Engineering, Institute of Chemical Technology in Prague, \\ Technická 5, 166 28, Prague 6, Czech Republic; ${ }^{2}$ Pacific Northwest National Laboratory, \\ Richland, WA 99352, USA; ${ }^{3}$ Division of Advanced Nuclear Engineering, Pohang University \\ of Science and Technology, Pohang, Republic of Korea \\ pavel.hrma@pnl.gov, fax 509-372-5997
}

\begin{abstract}
In this study, we present a model for the kinetics of multiple overlapping reactions.

Mathematical representation of the kinetics of gas-evolving reactions is crucial for the modeling of the feed-to-glass conversion in a waste-glass melter. The model simulates multiple gas-evolving reactions that occur during heating of a high-alumina high-level waste melter feed. To obtain satisfactory kinetic parameters, we employed Kissinger's method combined with least-squares analysis. The power-law kinetics with variable reaction order sufficed for obtaining excellent agreement with measured thermogravimetric analysis data.
\end{abstract}

Keywords: overlapping reactions, reaction kinetics, Kissinger method, glass melting, glass batch, TGA

\section{Introduction}

Successive and simultaneous reactions are common in reacting mixtures, and multiple overlapping reactions are typical in glass batches during their conversion to molten glass [1- 
19]. Yet hardly any mixture found in nature or industrial technology has as many components and undergoes as many reactions as melter feeds during vitrification of nuclear wastes $[20$, 21]. The waste itself contains compounds of 40 to 60 elements [22] that react with glassforming additives on heating. Consequently, the non-isothermal thermogravimetric analysis (TGA) of high-level waste melter feeds reveals multiple overlapping peaks on the $\mathrm{d} \xi / \mathrm{d} t$ versus $T$ curve, where $\xi$ is the conversion progress, $t$ is the time, and $T$ is the temperature. These reactions occur within the cold cap, a layer of melter feed floating on the pool of molten glass in the melter $[23,24]$. The feed is charged on the top of the cold cap, where the temperature is $\sim 100^{\circ} \mathrm{C}$, and as it moves towards the bottom, where the temperature is $\sim 1000^{\circ} \mathrm{C}$, it is converted to glass $[25,26]$. A model for the conversion kinetics is needed for the cold cap model that in turn is a part of the model of the melter.

In this paper, we analyze the gas evolution process as recorded by the non-isothermal TGA. We do not attempt to assess the mechanisms of individual gas-evolving reactions from solid and liquid components, which are both successive and simultaneous and include the release of chemically bonded water, reactions of nitrates with organics, and reactions of molten salts with solid silica. We merely assume that the reactions are independent and their rates can be described by the equation $-\mathrm{d} \xi_{i} / \mathrm{d} t=\mathrm{f}_{\mathrm{i}}\left(\xi_{i}\right) A_{i} \exp \left(-B_{i} / T\right)$, where $\mathrm{f}_{\mathrm{i}}\left(\xi_{i}\right)=\xi_{i}^{n_{i}}$ is a power-law function, $\xi$ is the degree of conversion, $A$ is the pre-exponential factor, $B$ is the activation energy, $n$ is the (apparent) reaction order, and the subscript $i$ stands for the $i^{\text {th }}$ reaction.

Our goal is to model the reaction kinetics in a way that is sufficient and adequate for modeling of the cold cap process. To this end, we deem the four-parameter simulation for each reaction satisfactory. These parameters are $A_{i}, B_{i}, n_{i}$, and $w_{i}$, the weight of the $i^{\text {th }}$ reaction (the fraction of the total mass loss caused by the $i^{\text {th }}$ reaction). Considering the number of reactions, this number of parameters is too large to effectively optimize with least-squares 
regression, especially for less distinct peaks. Therefore, we applied Kissinger's method [27] for the direct estimate of $B_{i}$ s based on the shift of the peak maximum temperature with the rate of heating and used least-squares optimization for the remaining parameters. The kinetics of reactions with overlapping peaks has been investigated since 1980s [28-36] and the twostep optimization was employed by several researchers $[30,31,32,36]$.

\section{Theory}

The mechanisms of reactions that occur during the conversion of melter feeds to glass are complex. Fortunately, the power-law function satisfactorily describes most of the gasevolving melting reactions monitored by the TGA, allowing us to choose the standard powerlaw kinetics, according to which the rate of gas-evolving reactions can be expressed as

$$
\frac{\mathrm{d} x_{i}}{\mathrm{~d} t}=A_{i}\left(1-x_{i}\right)^{n_{i}} \exp \left(-\frac{B_{i}}{T}\right)
$$

where $x_{i}$ is the fraction of material reacted in the $i^{\text {th }}$ reaction.

In his seminal paper, Kissinger [27] derived for $B_{i}$ the formula

$$
B_{i}=-\frac{\mathrm{d}\left(\ln \frac{\Phi}{T_{i m}^{2}}\right)}{\mathrm{d}\left(\frac{1}{T_{i m}}\right)}
$$

where $\Phi=\mathrm{d} T / \mathrm{d} t$ is the temperature increase rate and the subscript $m$ denotes the peak maximum $\left(\mathrm{d}^{2} x_{i} / \mathrm{d} t^{2}=0\right)$. This approximate formula is highly applicable for batch melting reactions, as shown in Appendix A. 
If $\Phi$ is constant and $n \neq 1$, integration of Eq. (1) yields

$$
x_{i}=1-\left[1+\frac{\left(n_{i}-1\right) A_{i}}{\Phi} \int_{0}^{T} \exp \left(-\frac{B_{i}}{T}\right) \mathrm{d} T\right]^{1 /\left(1-n_{i}\right)}
$$

Following Kissinger, who used Murray and White's approximation for the exponential integral [37], Eq. (3) becomes

$$
x_{i}=1-\left[1+\frac{\left(n_{i}-1\right) A_{i} T^{2}}{B_{i} \Phi}\left(1-\frac{2 T}{B_{i}}\right) \exp \left(-\frac{B_{i}}{T}\right)\right]^{1 /\left(1-n_{i}\right)}
$$

This expression allows us to eliminate $x$ from Eq. (1), thus expressing $\mathrm{d} x_{i} / \mathrm{d} T$ as a function of $T$ and $\Phi$ alone.

For multiple reactions that are mutually independent, we can write (using $T=T_{0}+\Phi t$ )

$$
\frac{\mathrm{d} x}{\mathrm{~d} T}=\frac{1}{\Phi} \sum_{i}^{N} w_{i} A_{i}\left(1-x_{i}\right)^{n_{i}} \exp \left(-\frac{B_{i}}{T}\right)
$$

where $x=\Sigma x_{i}$.

\section{Experimental}

Table 1 displays the composition of the melter feed used. As described elsewhere [21], this feed was formulated to vitrify a high-alumina high-level waste to produce glass of the composition (with mass fractions in parentheses): $\mathrm{SiO}_{2}(0.305), \mathrm{Al}_{2} \mathrm{O}_{3}(0.240), \mathrm{B}_{2} \mathrm{O}_{3}(0.152)$, $\mathrm{Na}_{2} \mathrm{O}(0.096), \mathrm{CaO}(0.061), \mathrm{Fe}_{2} \mathrm{O}_{3}(0.059), \mathrm{Li}_{2} \mathrm{O}(0.036), \mathrm{Bi}_{2} \mathrm{O}_{3}(0.011), \mathrm{P}_{2} \mathrm{O}_{5}(0.011), \mathrm{F}$ 
(0.007), $\mathrm{Cr}_{2} \mathrm{O}_{3}(0.005), \mathrm{PbO}(0.004), \mathrm{NiO}(0.004), \mathrm{ZrO}_{2}(0.004), \mathrm{SO}_{3}(0.002), \mathrm{K}_{2} \mathrm{O}(0.001)$, $\mathrm{MgO}(0.001)$, and $\mathrm{ZnO}(0.001)$. This glass was designed for the Hanford Tank Waste Treatment and Immobilization Plant, currently under construction at the Hanford Site in Washington State, USA.

The simulated melter feed was prepared, as described by Schweiger et al. [21], as slurry that was dried at $105^{\circ} \mathrm{C}$ overnight in an oven. For the TGA, feed samples of $10-60 \mathrm{mg}$ were placed in a Pt crucible from TA Instruments ${ }^{\odot}$ (New Castle, DE, U.S.A., SDT-Q600) and heated from ambient temperature $\left(\sim 25^{\circ} \mathrm{C}\right)$ to $1200^{\circ} \mathrm{C}$ at the rates $1,5,10,15,20$, and $50 \mathrm{~K} / \mathrm{min}$

Fig. 1 shows the TGA curves for the melter feed heated at several rates. As expected, the peaks shift to higher temperatures and the peak heights generally decrease as the rate of heating increases.

To deconvolute the TGA curve of $\mathrm{d} x / \mathrm{d} T$ versus $T$ for a series of $\Phi \mathrm{s}, T_{i m} \mathrm{~s}$ were determined as temperatures of the peak maxima or estimated for shoulders on larger peaks. From these data, with Eq. (2), we obtained $B_{i}$ s. Having predetermined $B_{i}$ s facilitated the application of the least squares analysis that we employed to fit the combined Eqs. (4) and (5) to measured $\mathrm{d} x / \mathrm{d} T$ versus $T$ data to obtain three independent parameters, $A_{i}, n_{i}$, and $w_{i}$, for each reaction.

\section{Results}

In our previous work [23], we fitted Eq. (5) with $n_{i}=1$ to experimental data, taking advantage of the fact that with $n_{i}=1$ one can calculate $A_{i}$ using the formula $A_{i}=$ $\left(B_{i} \Phi / T_{m i}{ }^{2}\right) \exp \left(B / T_{m i}\right)$. Fig. 2 displays the results of the least-squares analysis for eight major reactions. Clearly, the agreement of measured and calculated curves is far from satisfactory: 1) the conversion rates are underestimated between peaks 1 and 2 and peaks 4 and 5;2) the 
long tail of peak 8 is not well simulated; 3) some calculated peaks overshoot the measured peaks.

To improve the model, we upgraded it to the $n^{\text {th }}$-order reaction model and added reaction $1 \mathrm{~A}$ between reactions 1 and 2 . For the overlapped reactions, such as $1 \mathrm{~A}$, we obtained the $T_{m}$ by subtracting the neighboring peaks as calculated from the measured curve. Figure 3 displays the Kissinger plot for all nine peaks. Table 2 lists the values of $B$ calculated with Eq. (2), together with the standard deviations and the coefficients of determination, $R^{2}$. Table 3 lists the result of the least-squares analysis and Fig. 4 displays the deconvoluted TGA curve for the heating rate $15 \mathrm{~K} / \mathrm{min}$.

As Fig. 4 shows, peak 8 possesses a long tail, which is probably caused by a process with a temperature-dependent $B_{8}$ or by a conglomerate of multiple reactions. The algorithm for the least-squares analysis simulates this long tail via a high value of the reaction order. The fitted $n_{i}$ s were also abnormally high for some other peaks (peak 5 , as can be seen in Table 3 , and peaks $1,1 \mathrm{~A}$, and 7 in similar fits to some other heating rates). Because these elongated peaks unduly influence the neighboring peaks, we constrained $n_{i}$ s for peaks $1,1 \mathrm{~A}, 5$, and 7 to $0<n_{i}$ $<2$ but we left peak 8 to retain an unrestricted reaction order to represent the evolution of gas at high temperatures as faithfully as possible. Peak 8 gases might be responsible for foaming that affects, and perhaps even controls, the melting rate of the cold cap in the waste glass melter [23, 25]. Tables 4,5 and 6 present the values of the kinetic coefficients $A_{i}$ and $n_{i}$ and the reaction weights, $w_{i}$, from fitting joined Eqs. (4) and (5) to the TGA curves.

Assuming that the kinetics of individual reactions does not change with the heating rate (Kissinger's formula is based on this assumption), the parameters $A_{i}$ and $n_{i}$ are independent of $\Phi$. Indeed, as the very small values of standard deviation in Table 4 indicate, $\log \left(A_{i}\right)$ values are almost constant and their averages represent the averaged pre-exponential factors for individual reactions across the heating rates employed. 
Somewhat larger standard deviations of $n_{i}$ s (up to $39 \%$ ) indicate differences in the shapes of the peaks, but no trends can be discerned from the values. The $n_{i}$ values of peaks with negligible weights (those in parentheses) were not included in the averages listed in Table 5 (see the virtually nonexistent peak 5 in Figs. 4 and 5). Note that $n_{i}=2$ was imposed as the upper limit for peaks $1,1 \mathrm{~A}, 5$ and 7.

On the other hand, $w_{i}$ can vary with $\Phi$, as consecutive reactions may be influenced by preceding ones, i.e., reactions that run at a lower temperature affect the reactions that follow them, especially when the heating rate is low. Accordingly, some reactions are not independent, but not to the extent that would invalidate the superposition relationship, Eq. (5).

Table 7 lists $w_{i}$ values recalculated using the average values of $A_{i}$ and $n_{i}$ listed in Tables 4 and 5 . Since $w_{i}$ is the fraction of the material reacted by $i^{\text {th }}$ reaction, the sum of the $w_{i}$ s for all reactions, $w=0.202 \pm 0.003$, represents the total mass loss during the heat treatment. Table 7 also lists the measured values of fractional mass loss, $w_{\text {TGA }}$. Fig. 6 plots the corresponding comparisons of measured and calculated TGA curves together with the peak deconvolution.

\section{Discussion}

Our present objective is describing the gas evolution from a melter feed in a way suitable for implementing its kinetics into a mathematical model of the cold cap response to the conditions in the glass melter. To this end, Eq. (5) with the numerical values of parameters is adequate even though the $\mathrm{f}_{\mathrm{i}}\left(x_{i}\right)=\left(1-x_{i}\right)^{n_{i}}$ used does not represent the reaction mechanism. Provided that the values of $A_{i}$ and $n_{i}$ are independent of $\Phi$, the only task left is to construct reasonable functions of $w_{i}$ s versus $\Phi$, at least for the rates within the interval of 5 to $20 \mathrm{~K} / \mathrm{min}$ that exist within the cold cap. As evidenced from Table 7 , the $w_{i}$ versus $\Phi$ values significantly deviate from constancy, at least for some peaks. Only $w_{1}$ is virtually independent of $\Phi$. While some $w_{i}$ s fluctuate because of experimental error, some peaks exhibit discernible trends for 
which an approximation function $w_{i}(\Phi)$ could possibly be constructed. The experimental errors are probably associated with the small sample size; the tiny Pt crucibles contained the sample mass of $30 \mathrm{mg}$ in average, which is rather small for a mixture of granular materials. Therefore, an instrument that allows larger samples will be used for future experiments.

Three sources of potential errors arise from various approximations of the model itself: 1) approximation of the exponential integral as a truncated series, 2) approximation used in the development of Kissinger's formula, Eq. (2), and 3) shift in $T_{m}$ caused by peak overlapping. The third issue, the shift in $T_{m}$, can be seen in Fig. 1 and is illustrated in Fig. 7. As discussed in Appendix A, these approximations have negligible impact on the evaluation of the TGA curves under consideration.

To further verify that Kissinger's formula provides correct values of $B$ in spite of the $T_{m}$ shift, we optimized $B_{i}$ s directly from data. Separate fitting to each heating rate with the average values of $A_{i}$ and $n_{i}$ and the $w_{i}$ values listed in Table 7 resulted in fluctuating $B_{i}$ s with averages close to the values from Kissinger's formula, though with lower standard deviations. Fitting the model to all data for all heating rates at once with the same $A_{i}, n_{i}$ and the $w_{i}$ values as for the separate fitting resulted in $B_{i}$ s that were close to both the averages and $B_{i}$ s obtained using Kissinger's method—-see Table 8. Thus, additional fitting did not bring any improvement worth considering.

Because of the compensation effect between $B_{i}$ and $A_{i}$ that results from the relatively narrow temperature interval in which the $i^{\text {th }}$ reaction starts and is complete, nearly the same fit can be obtained from relatively wide ranges of $B_{i}$ and $A_{i}$ combinations [28]. For this reason, Kissinger's method appears preferable to fitting of $B_{i}$ and $A_{i}$ simultaneously. A similar conclusion seems to have been reached by others $[30-33,36]$.

\section{Conclusions}


The kinetic model with empirical reaction order yields a reasonable simulation for the kinetics of multiple overlapping reactions that are typical of melting glass batches. The power-law model employed was successful even though it does not represent the mechanism of reactions between multiple granular solids and ionic and glass-forming melts produced in glass batches at higher temperatures. Thus, each reaction was sufficiently characterized with four coefficients, i.e., the activation energy, the pre-exponential factor, the reaction order, and the weight (the fraction reacted), of which only the weight is a weak function of the rate of heating. To avoid problems with the compensation effect between the activation energy and the pre-exponential factor, we successfully combined Kissinger's method with least-squares optimization. The three kinetic coefficients plus the reaction weights thus obtained can be used in an advanced model for glass melting in the cold cap.

\section{Acknowledgements}

This research was supported by the U.S. Department of Energy Federal Project Office Engineering Division for the Hanford Tank Waste Treatment and Immobilization Plant and by the WCU (World Class University) program through the National Research Foundation of Korea funded by the Ministry of Education, Science and Technology (R31 - 30005). Richard Pokorny is pleased to acknowledge support from Czech Grant Agency (GACR No.

P106/11/1069). The authors are grateful to Albert Kruger for his assistance and guidance and to Dong-Sang Kim and Jaehun Chun for insightful discussions.

\section{Appendix A. -Kissinger's formula}

Consider the reaction rate in the form

$$
\dot{x}=A \mathrm{f}(x) e^{-B / T}
$$


where $\mathrm{f}(x)$ is the reaction mechanism function and the dot above the symbol denotes the time derivative. Lists of various $\mathrm{f}(x)$ abound in the literature $[31,35,37,39,40]$. If the temperature rises at a constant heating rate, $\Phi$, then, by setting $\ddot{x}=0$, we obtain the formula

$$
\frac{B \Phi}{T_{m}^{2}}=-A f^{\prime}\left(x_{m}\right) e^{-B / T_{m}}
$$

where $\mathrm{f}^{\prime}=\mathrm{df} / \mathrm{d} x$, and the subscript $m$ denotes the maximum reaction rate. Introducing the notation $Y=\Phi / T_{m}{ }^{2}, \mathrm{f}_{m}{ }^{\prime}=\mathrm{f}^{\prime}\left(x_{m}\right)$, and $\Theta=1 / T_{m}$, Eq. (A.2) becomes

$$
B Y=-A \mathbf{f}_{m}^{\prime} e^{-B \Theta}
$$

By differentiation with respect to $\Theta$, we obtain $\mathrm{d} Y / \mathrm{d} \Theta=-B Y(1+\varepsilon)$, where $\varepsilon=-B^{-1} \mathrm{~d} \ln \left(-\mathrm{f}_{m}{ }^{\prime}\right) / \mathrm{d} \Theta$. This equation was derived by Criado and Ortega [39]. Here we have assumed that $B$ is independent of $T_{m}$. This may not be always the case [41]. For example, for diffusion-controlled processes in glasses and polymers, $B$ is a function of temperature.

Provided that $x_{m}$ changes little with $T_{m}, \varepsilon$ can be neglected and $B=-\mathrm{d} \ln (Y) / \mathrm{d} \Theta$, which is the famous Kissinger formula [27], usually presented as

$$
B=-\frac{\mathrm{d}\left(\ln \frac{\Phi}{T_{m}^{2}}\right)}{\mathrm{d}\left(\frac{1}{T_{m}}\right)} .
$$

To prove that $\varepsilon<<1$, we integrate Eq. (A.1) and use Eq. (A.3) to eliminate $\Phi$, obtaining 


$$
\mathrm{g}_{\mathrm{m}} \mathrm{f}_{\mathrm{m}}^{\prime}=-z_{m}^{2} e^{z_{m}} \int_{z_{m}}^{\infty} z^{-2} e^{-z} \mathrm{~d} z
$$

where $\mathrm{g}_{m}=\int_{0}^{x_{m}} \mathrm{~d} x / \mathrm{f}(x)$ and $z=B / T$. Using Murray and White's approximation [37] of the exponential integral, Eq. (A.6) becomes [27]

$$
2 T_{m}=B\left(1+\mathrm{g}_{m} \mathrm{f}_{m}^{\prime}\right)
$$

Based on this equation, recollecting that $\varepsilon=-B^{-1} \mathrm{~d} \ln \left(-\mathrm{f}_{m}{ }^{\prime}\right) / \mathrm{d}\left(1 / T_{m}\right)$, and with some algebra, one obtains for the $n^{\text {th }}$ order reaction, i.e., $\mathrm{f}(x)=(1-x)^{n}$, the following expression:

$$
\varepsilon=\frac{\frac{T_{m}}{B}}{1-\frac{B}{2(1-n) T_{m}}} .
$$

With $T_{m} / B<0.05, \varepsilon<0.025$ for $1<n<10$ (see Fig. A1), but it is deduced that Kissinger's formula fails for large values of $T_{m} / B$ and $n$. The smallness of $\varepsilon$ was asserted for various other reaction mechanisms with $T_{m} / B$ small enough by Criado and Ortega [39] who used the approximation by Senum and Yang [42] and concluded that $\varepsilon<0.05$ as long as $B / T_{m}>10$ for commonly used functions $\mathrm{f}(x)$; Senum and Yang approximation differs little from the simpler Murray and White approximation if $T / B<0.05$.

Eq. (A.7) can be used to express $x_{m}$ as a function of $T_{m}$ for various reaction mechanisms. Fig. A2 shows $x_{m}$ for the $n^{\text {th }}$ order reaction as a function of both $n$ and $T_{m} / B$, confirming that that $x_{m}$ changes little with $T_{m}$ for the range of $T_{m} / B$ values typical in glass melting. 
To explore the effect of overlapping peaks on $B_{i}$, let us start from Eq. (5) in the form

$$
\dot{x}=w_{i} \mathrm{f}_{i}(x) A_{i} e^{-B_{i} / T}+\sum_{j \neq i} w_{j} \dot{x}_{j}
$$

where $\dot{x}_{j}=w_{j} \mathrm{f}_{j}(x) A_{j} e^{-B_{j} / T}$. Applying to Eq. (A.9) the condition for the $i^{\text {th }}$ reaction maximum on the TGA curve, i.e., $\ddot{x}=0$ at each $T=T_{m i}$, we obtain

$$
0=\dot{x}_{i}\left(T_{m i}\right)\left[\frac{B_{i} \Phi}{T_{m i}^{2}}+w_{i} \mathrm{f}_{i}^{\prime}\left(x_{m i}\right) A_{i} e^{-B_{i} / T_{m i}}\right]+\sum_{j \neq i} w_{j} \ddot{x}_{j}\left(T_{m i}\right)
$$

where the prime denotes the derivative. Rearranging and taking a logarithm, Eq. (A.10) becomes

$$
\ln \frac{\Phi}{T_{m i}^{2}}+\ln \left[1+\frac{T_{m i}^{2} \sum_{j \neq i} w_{j} x_{j}^{\prime \prime}\left(T_{m i}\right)}{B_{i} x_{i}^{\prime}\left(T_{m i}\right)}\right]=\ln \left[-\frac{w_{i} \mathrm{f}_{i}^{\prime}\left(x_{m i}\right) A_{i}}{B_{i}}\right]-\frac{B_{i}}{T_{m i}}
$$

where $x^{\prime \prime}=\mathrm{d}^{2} x / \mathrm{d} T^{2}$. The Kissinger formula now assumes the form

$$
-B_{i}=\frac{\mathrm{d} \ln \frac{\Phi}{T_{m i}^{2}}}{\mathrm{~d} \frac{1}{T_{m i}}}+\frac{\mathrm{d} \ln \left[1+\frac{T_{m i}^{2} \sum \sum_{j \neq i} w_{j} x_{j}^{\prime \prime}\left(T_{m i}\right)}{B_{i} x_{i}^{\prime}\left(T_{m i}\right)}\right]}{\mathrm{d} \frac{1}{T_{m i}}}-\frac{\mathrm{d} \ln \left[-\mathrm{f}_{i}^{\prime}\left(x_{m i}\right)\right]}{\mathrm{d} \frac{1}{T_{m i}}} .
$$


We have already shown that the third term on the right hand side can be neglected for high-temperature reactions. The second term is negligible if

$$
\sum_{j \neq i} w_{j} x_{j}^{\prime \prime}\left(T_{m i}\right)<<\frac{B_{i}}{T_{m i}^{2}} x_{i}^{\prime}\left(T_{m i}\right) .
$$

Then Eq. (A.11) becomes Eq. (A.4). If only two peaks overlap, inequality (A.13) reduces to $w_{j} x_{j}^{\prime \prime}\left(T_{m i}\right)<<\frac{B_{i}}{T_{m i}^{2}} x_{i}^{\prime}\left(T_{m i}\right)$.

Let us check this inequality with peaks 2 and 3 as shown in Fig. 7, where the first maximum associated with reaction $2(i \equiv 2)$ is shifted to a higher temperature because of the overlapping peak of reaction $3(j \equiv 3)$. With the values $w_{3}=0.054$ and $x_{3}^{\prime \prime}\left(T_{m 2}\right)=1.67 \times 10^{-4}$, we get $w_{2} x_{2}^{\prime \prime}\left(T_{m 2}\right)=9.03 \times 10^{-6} \mathrm{~K}^{-2}$; with $B_{2}=1.88 \times 10^{4} \mathrm{~K}, T_{m 2}=521 \mathrm{~K}$, and $x_{2}^{\prime}\left(T_{m 2}\right)=$ 0.665 , we have and $B_{2} T_{m 2}^{-2} x_{2}^{\prime}\left(T_{m 2}\right)=4.60 \times 10^{-2} \mathrm{~K}^{-2}$. Hence, inequality (A.13) is satisfied for this example. It is also likely to be satisfied if the central peak overlaps with two peaks on the opposite sides. Then the two values of $w_{j} x_{j}^{\prime \prime}\left(T_{m i}\right)$ of the side peaks have opposite signs.

However, if the neighboring peaks are close to each other and the slope $x_{j}^{\prime \prime}=\mathrm{d} x_{j}^{\prime} / \mathrm{d} T$ at $T$ $=T_{m i}$ is large, inequality (A.13) is not satisfied. As Wilburn [33] showed, it is impossible to determine the kinetic coefficients of such reactions. This may be so, yet any model that simulates the measured data with a sufficient accuracy is suitable for mathematical representation of the response of the reacting mixture to increasing temperature within the realistic rate of heating. Here our objective is practical application of the model for a specific response rather than constructing molecular mechanisms of individual reactions. 
For $\mathrm{f}(x)=(1-x)^{n}$, the relationship between the peak height an $T_{m}$ can be derived from Eqs. (A.1) and (A.2). The resulting expression is:

$$
\frac{\mathrm{d} x\left(T_{m}\right)}{\mathrm{d} t}=\frac{\Phi B}{n T_{m}^{2}}\left[\frac{1}{n}-\left(\frac{1}{n}-1\right) \frac{2 T_{m}}{B}\right]^{\frac{1}{n-1}} .
$$

This expression contains both $\Phi$ and $T_{m}$, but $T_{m}$ changes in response to $\Phi$ according to the formula

$$
\Phi=\frac{A T_{m}^{2}}{B}\left[1+(n-1) \frac{2 T_{m}}{B}\right] \exp \left(-\frac{B}{T_{m}}\right)
$$

The line in Fig. B1 plots the peak height, $\mathrm{d} x\left(T_{m}\right) / \mathrm{d} t$, against $T_{m}$ and $\Phi$ for peak 3 . The data points in Fig. B1 show the heights of deconvoluted peaks (the diamonds) and the heights of the peaks on the TGA curves (the squares). Note that deconvoluted peak heights ale located close (virtually on) the line representing formulas (B.1) and (B.2), whereas the points corresponding to the peak heights on the TGA curves are mostly above the lines and somewhat shifted as discussed in Appendix A.

Finally, by using Eq. (A.4), we have

$$
\Phi=\Phi_{0}\left(\frac{T_{m}}{T_{m 0}}\right)^{2} \exp \left[-B\left(\frac{1}{T_{m}}-\frac{1}{T_{m 0}}\right)\right] .
$$

This function is illustrated in Fig. B2. By Eq. (B.3), the relationship between $T_{m}$ and $\Phi$ is independent of the reaction mechanism. 


\section{References}

1. Wilburn FW, Thomasson CV. The application of differential thermal analysis and thermogravimetric analysis to the study of reactions between glass-making materials. Part 1. The sodium carbonate-silica system. J. Soc. Glass Technol. 1958;42:158T-175T.

2. Thomasson CV, Wilburn FW. The application of differential thermal analysis and thermogravimetric analysis to the study of reactions between glass-making materials. Part 2. The calcium carbonate-silica system with minor batch additions. Phys. Chem. Glasses $1960 ; 1: 52-69$.

3. Wilburn FW, Thomason CV. The application of differential thermal analysis and thermogravimetric analysis to the study of reactions between glass-making materials. Part 3. The sodium carbonate-silica system. Phys. Chem. Glasses 1961;2:126-131.

4. Wilburn FW, Thomason CV. The application of differential thermal analysis and differential thermogravimetric analysis to the study of reactions between glass-making materials. Part 4. The sodium carbonate-silica-alumina system. Phys. Chem. Glasses 1963;4:91-98.

5. Wilburn FW, Metcalf SA, Warburton RS. Differential thermal analysis, differential thermogravimetric analysis, and high temperature microscopy of reactions between major components of sheet glass batch. Glass Technol 1965;6:107-114.

6. Ott WR, McLaren MG, Harsell WB. Thermal analysis of lead glass batch. Glass Technology 1972;13:154-160.

7. Bader E. Combined method of differential thermal analysis and evolved gas analysis with the heat conductivity detector for study of Pyrex batches. Silikattechnik 1977;28:23-28.

8. Bader E. Thermoanalytical investigation of melting and fining of Thüringen laboratory glassware. Silikattechnik 1978;29:84-87. 
9. Bader E. Melting reactions in B-3.3- glass batches with soda and sodium nitrate as alkali sources . Silikattechnik 1979;30:112-115.

10. Bader E. Effect of cullet on melting reactions in B-3.3- and Na-Ca-silica glass batches. Silikattechnik 1979;30:269-272.

11. Mukerji J, Nandi AK, Sharma KD. Reaction in container glass batch. Ceram. Bull. $1979 ; 22: 790-793$.

12. Abe O, Utsunomiya T, Hoshino Y. The reaction of sodium nitrate with silica. Bull. Chem. Soc. Jpn. 1983;56:428-433.

13. Taylor TD, Rowan KC. Melting reactions of soda-lime-silicate glasses containing sodium sulfate. J. Amer. Ceram. Soc. 1983;66:C-227-228.

14. Lindig M, Gehrmann E, Frischat GH. Melting behavior in the system $\mathrm{SiO}_{2}-\mathrm{K}_{2} \mathrm{CO}_{3}-$ $\mathrm{CaMg}\left(\mathrm{CO}_{3}\right)_{2}$ and $\mathrm{SiO}_{2}-\mathrm{K}_{2} \mathrm{CO}_{3}-\mathrm{PbO}$. Glastech. Ber. 1985;58:27-32.

15. Sheckler CA, Dinger DR. Effect of particle size distribution on the melting of soda-limesilica glass. J. Amer. Ceram. Soc. 1990;73:24-30.

16. Hong KS, Speyer RE. Thermal analysis of reactions in soda-lime-silicate glass batches containing melting accelerants: I, one- and two-component systems. J. Amer. Ceram. Soc. 1993;76:598-604.

17. Hong KS, SW Lee, Speyer RE. Thermal analysis of reactions in soda-lime-silicate glass batches containing melting accelerants: II, Multicomponent systems. J. Amer. Ceram. Soc. $1993 ; 76: 605-608$.

18. Savard ME, Speyer RE. Effect of particle size on the fusion of soda-lime-silicate glass containing NaCl. J. Amer. Ceram. Soc. 1993;76:671-677.

19. Ray HS. Introduction to melts: molten salts, slags and glasses. Allied Publishers Pvt Ltd; 2006. 
20. Hrma P, Schweiger MJ, Humrickhouse CJ, Moody JA, Tate RM, Rainsdon TT, TeGrotenhuis NE, Arrigoni BM, Marcial J, Rodriguez CP, Tincher BH. Effect of glassbatch makeup on the melting process. Ceram.-Silik. 2010;54:193-211.

21. Schweiger MJ, Hrma P, Humrickhouse CJ, Marcial J, Riley BJ, TeGrotenhuis NE. Cluster formation of silica particles in glass batches during melting. J Non-Cryst Solids. 2010;356:1359-1367.

22. Kim D, Schweiger MJ, Rodriguez CP, Lepry WC, Lang JB, Crum JV, Vienna JD, Johnson FC, Marra JC, Peeler DK. Formulation and characterization of waste glasses with varying processing temperature. PNNL-20774, EMSP-RPT-00. 2011.

23. Hrma P, Pierce DA, Pokorny R. Thermal Analysis of Waste Glass Melter Feeds. In: Proceedings of the International Symposium on Radiation Safety Management, p. 217222, Gyeongju, Republic of Korea, November 2-4, 2011.

24. Pierce DA, Hrma P, Marcial J, Riley BJ, Schweiger MJ. Effect of alumina source on ease of melting of glass batch, Int J Appl Glass Sci, submitted.

25. Pokorny R, Hrma P. Mathematical modeling of cold cap. Submitted.

26. Hrma P, Kruger AA. Pokorny R. Nuclear waste vitrification efficiency: cold cap reactions. RPI University Conference. Troy, New York. 2011.

27. Kissinger HE. Reaction Kinetics in Differential Thermal Analysis. Anal Chem. 1957;29:1702-1706.

28. Marcu V, Segal E. Kinetic analysis of sequence of two consecutive reactions from thermogravimetric data under non-isothermal conditions. I. Calculated thermograms. Thermochim Acta 1980;35:43-49.

29. Ito N. Separation of DTA peaks of a multistage reaction. Thermochim Acta 1984;76:121126. 
30. Boy S, Böhme K. Kinetic analysis of additively overlapping reactions. Part 1. Description of an optimization method and its use for the separation of peaks. Thermochim Acta $1984 ; 75: 263-273$.

31. Criado JM, González M, Ortega A, Real C. Discrimination of the kinetic model of overlapping solid-state reactions from non-isothermal data. J Therm Anal Calorim. $1988 ; 34: 1387-1396$.

32. Slovák V. Determination of kinetic parameters by direct non-linear regression from TG curves. Thermochim Acta 2001;372:175-182.

33. Wilburn FW. Kinetics of overlapping reactions. Thermochim Acta 2000;354:99-105.

34. Barbadillo F, Fuentes A, Naya S, Cao R, Mier JL, Artiaga R. Evaluating the logistic mixture model on real and simulated TG curves. J Term Anal Calorim 2007;87:223-227.

35. Robinson R, Patisson F, Björkman B. Low temperature reactivity in agglomerates containing iron oxide. J Therm Anal Calorim 2011;103:185-193.

36. Primig S, Leitner H. Separation of overlapping retained austenite decomposition and cementite precipitation reactions during tempering of martensitic steel by means of thermal analysis. Thermochim Acta 2011;526:111-117.

37. Murray P, White J. Kinetics of the thermal dehydration of clays. IV. Interpretation of the differential thermal analysis of the clay minerals. Trans Brit Ceram Soc 1955;54:204-237.

38. Ozawa T. Kinetic analysis of derivative curves in thermal analysis. J Therm Anal $1970 ; 2: 301-324$

39. Criado JM, Ortega A. Non-isothermal transformation kinetics: Remarks on the Kissinger method. J Non-Cryst Solids 1986;87:302-311.

40. Sánchez-Jiménez PE, Criado JM, Pérez-Mequeda LA. Kissinger kinetic analysis of data obtained under different heating schedules. J Therm Anal Calorim. 2008;94:427-432. 
41. Vyazovkin S. On the phenomenon of variable activation energy for condensed phase reactions. New J Chem. 2000;24:913-917.

42. Senum GI, Yang RT. Rational approximations of the integral of the Arrhenius function. J Therm Anal. 1977;11:445-447. 


\section{Figure captions}

Fig. 1 Measured TGA curves for melter feed heated at various rates

Fig. 2 Measured and calculated curves for melter feed heated at $10 \mathrm{~K} / \mathrm{min}$ for first-order reaction model

Fig. 3 Kissinger plot for melter feed TGA peaks

Fig. 4 Deconvoluted TGA curve for $\Phi=15 \mathrm{~K} / \mathrm{min}$

Fig. 5 Deconvoluted TGA curve for $\Phi=5 \mathrm{~K} / \mathrm{min}$

Fig. 6 Measured (solid line) and calculated (dashed line) TGA curves and deconvolution peaks for individual heating rates using average $A_{i}$ and $n_{i}$

Fig. 7 Effect of peak overlapping on measured $T_{m}$

Fig. A1 Error $(\varepsilon)$ in $B$ versus $n$ for three values of $T_{m} / B$ shown legend

Fig. A2 $x_{m}$ versus $n$ and $T_{m} / B$ (see legend)

Fig. B1 Peak height as $\mathrm{d} x\left(T_{m}\right) / \mathrm{d} t$ versus $T_{m}$ and $\Phi\left(A=2.93 \times 10^{10} \mathrm{~s}^{-1}, B=1.611 \times 10^{4} \mathrm{~K}, n=\right.$ 0.54)

Fig. B2 $T_{m}$ versus $\Phi$ for $B=1.6 \times 10^{4} \mathrm{~K}$ and several combinations of $T_{m 0}$ and $\Phi_{0}$ [see Eq. (B3)] as shown in legend 
Table 1. Melter Feed Compositions in $\mathrm{g} / \mathrm{kg}$ glass (main components)

\begin{tabular}{|c|c|c|c|}
\hline Chemical & Mass & Chemical & Mass \\
\hline $\mathrm{Al}(\mathrm{OH})_{3}$ & 367.50 & $\mathrm{Na}_{2} \mathrm{SO}_{4}$ & 3.57 \\
\hline $\mathrm{H}_{3} \mathrm{BO}_{3}$ & 269.83 & $\mathrm{Bi}(\mathrm{OH})_{3}$ & 12.80 \\
\hline $\mathrm{CaO}$ & 60.80 & $\mathrm{Na}_{2} \mathrm{CrO}_{4}$ & 11.13 \\
\hline $\mathrm{Fe}(\mathrm{OH})_{3}$ & 73.83 & $\mathrm{KNO}_{3}$ & 3.03 \\
\hline $\mathrm{Li}_{2} \mathrm{CO}_{3}$ & 88.3 & $\mathrm{NiCO}_{3}$ & 6.33 \\
\hline $\mathrm{Mg}(\mathrm{OH})_{2}$ & 1.70 & $\mathrm{~Pb}\left(\mathrm{NO}_{3}\right)_{2}$ & 6.17 \\
\hline $\mathrm{NaOH}$ & 99.53 & $\mathrm{Fe}\left(\mathrm{H}_{2} \mathrm{PO}_{2}\right)_{3}$ & 12.43 \\
\hline $\mathrm{SiO}_{2}$ & 305.03 & $\mathrm{NaF}$ & 14.73 \\
\hline $\mathrm{Zn}\left(\mathrm{NO}_{3}\right)_{2} \cdot 4 \mathrm{H}_{2} \mathrm{O}$ & 2.67 & $\mathrm{NaNO}_{2}$ & 3.40 \\
\hline \multirow[t]{2}{*}{$\mathrm{Zr}(\mathrm{OH})_{4} \cdot 0.654 \mathrm{H}_{2} \mathrm{O}$} & 5.50 & $\mathrm{Na}_{2} \mathrm{C}_{2} \mathrm{O}_{4} \cdot 3 \mathrm{H}_{2} \mathrm{O}$ & 1.30 \\
\hline & & Total & 1349.6 \\
\hline
\end{tabular}

Table 2. Values of activation energy, $B_{i}$, its standard deviation, $s$, and coefficient of determination, $R^{2}$.

\begin{tabular}{l|ccc} 
Peak & $B_{i}\left[10^{4} \mathrm{~K}\right]$ & $s\left[10^{4} \mathrm{~K}\right]$ & $R^{2}$ \\
\hline Peak 1 & 2.25 & 0.18 & 0.974 \\
Peak 1A & 2.04 & 0.17 & 0.973 \\
Peak 2 & 1.88 & 0.06 & 0.996 \\
Peak 3 & 1.61 & 0.12 & 0.977 \\
Peak 4 & 1.83 & 0.11 & 0.986 \\
Peak 5 & 4.49 & 0.32 & 0.979 \\
Peak 6 & 2.98 & 0.42 & 0.926 \\
Peak 7 & 3.17 & 0.31 & 0.962 \\
Peak 8 & 2.60 & 0.60 & 0.862
\end{tabular}

Table 3. Optimized values of $n_{i}, w_{i}$, and $\log \left(A_{i} / \mathrm{s}^{-1}\right)$ for $\Phi=15 \mathrm{~K} / \mathrm{min}$.

\begin{tabular}{l|ccccccccc} 
Peak & 1 & $1 \mathrm{~A}$ & 2 & 3 & 4 & 5 & 6 & 7 & 8 \\
\hline$n_{i}$ & 2.73 & 1.83 & 1.09 & 0.51 & 2.11 & 12.03 & 0.79 & 1.66 & 3.44 \\
$w_{i}$ & 0.010 & 0.008 & 0.026 & 0.051 & 0.036 & 0.016 & 0.010 & 0.031 & 0.016 \\
$\log \left(A_{i}\right)$ & 20.24 & 17.09 & 14.06 & 10.49 & 11.57 & 27.94 & 16.96 & 17.32 & 12.93
\end{tabular}

Table 4. Values of $\log \left(A_{i} / \mathrm{s}^{-1}\right)$, average values, standard deviations, and relative standard deviations (RSD) for Peaks 1-8.

\begin{tabular}{r|ccccccccc}
$\Phi\left[\mathrm{K} \mathrm{min}^{-1}\right]$ & 1 & $1 \mathrm{~A}$ & 2 & 3 & 4 & 5 & 6 & 7 & 8 \\
\hline 1 & 20.28 & 16.93 & 13.98 & 10.41 & 11.53 & 28.02 & 16.70 & 17.24 & 12.41 \\
5 & 20.35 & 17.16 & 14.05 & 10.54 & 11.57 & 28.04 & 16.98 & 17.26 & 12.79 \\
10 & 20.15 & 17.05 & 14.03 & 10.34 & 11.36 & 28.37 & 17.08 & 17.41 & 12.67 \\
15 & 20.24 & 17.09 & 14.06 & 10.49 & 11.57 & 27.94 & 16.96 & 17.32 & 12.93 \\
20 & 20.17 & 17.01 & 14.03 & 10.52 & 11.64 & 27.95 & 16.81 & 17.33 & 12.85 \\
50 & 20.34 & 17.07 & 14.01 & 10.47 & 11.41 & 28.09 & 16.85 & 17.37 & 12.52 \\
Average & 20.26 & 17.05 & 14.03 & 10.46 & 11.51 & 28.07 & 16.90 & 17.32 & 12.69 \\
Stdev & 0.08 & 0.07 & 0.03 & 0.07 & 0.10 & 0.14 & 0.12 & 0.06 & 0.18 \\
RSD & 0.004 & 0.004 & 0.002 & 0.007 & 0.009 & 0.005 & 0.007 & 0.003 & 0.014
\end{tabular}


Table 5. Values of $n_{i}$, average values, standard deviations (values in parentheses were not included), and relative standard deviations for Peaks 1-8.

\begin{tabular}{r|ccccccccc}
$\Phi\left[\mathrm{K} \mathrm{min}^{-1}\right]$ & 1 & $1 \mathrm{~A}$ & 2 & 3 & 4 & 5 & 6 & 7 & 8 \\
\hline 1 & 2.00 & 1.90 & 0.71 & 0.39 & 3.39 & $(1.19)$ & 1.81 & $(0.10)$ & 2.05 \\
5 & 2.00 & 2.00 & 0.93 & 0.62 & 2.23 & $(0.61)$ & 1.00 & 1.29 & 3.13 \\
10 & 2.00 & 1.32 & 1.30 & 0.56 & 1.79 & 2.00 & 0.95 & 2.00 & 5.31 \\
15 & 2.00 & 1.99 & 1.09 & 0.50 & 2.37 & 2.00 & 1.58 & 1.15 & 3.59 \\
20 & 2.00 & 2.00 & 1.08 & 0.57 & 2.42 & 2.00 & 1.78 & $(0.55)$ & 4.70 \\
50 & 2.00 & 2.00 & 1.23 & 0.61 & 1.04 & 2.00 & 2.66 & 0.90 & 4.41 \\
Average & 2.00 & 1.87 & 1.06 & 0.54 & 2.21 & 2.00 & 1.63 & 1.33 & 3.87 \\
Stdev & 0.00 & 0.27 & 0.21 & 0.08 & 0.77 & 0.00 & 0.63 & 0.47 & 1.18 \\
RSD & 0.00 & 0.14 & 0.20 & 0.15 & 0.35 & 0.00 & 0.39 & 0.35 & 0.30
\end{tabular}

Table 6. Values of $w_{i}$ and the total fraction reacted, $w=\Sigma w_{i}$, for Peaks $1-8$.

\begin{tabular}{r|cccccccccc}
$\Phi\left[\mathrm{K} \mathrm{min}^{-1}\right]$ & 1 & $1 \mathrm{~A}$ & 2 & 3 & 4 & 5 & 6 & 7 & 8 & $w$ \\
\hline 1 & 0.009 & 0.008 & 0.026 & 0.052 & 0.041 & 0.000 & 0.045 & 0.000 & 0.018 & 0.198 \\
5 & 0.007 & 0.011 & 0.027 & 0.055 & 0.037 & 0.000 & 0.034 & 0.015 & 0.022 & 0.207 \\
10 & 0.008 & 0.007 & 0.031 & 0.049 & 0.031 & 0.002 & 0.023 & 0.028 & 0.023 & 0.203 \\
15 & 0.008 & 0.010 & 0.025 & 0.051 & 0.038 & 0.001 & 0.036 & 0.009 & 0.023 & 0.202 \\
20 & 0.008 & 0.010 & 0.023 & 0.049 & 0.040 & 0.003 & 0.042 & 0.002 & 0.025 & 0.203 \\
50 & 0.007 & 0.012 & 0.024 & 0.055 & 0.026 & 0.010 & 0.050 & 0.005 & 0.013 & 0.201
\end{tabular}

Table 7. Values of $w_{i}$ based on the average values of $A_{i}$ and $n_{i}$ listed in Tables 4 and 5, $w=$ $\Sigma w_{i}$, and the total fractional mass loss as measured by TGA, $w_{\mathrm{TGA}}$.

$\begin{array}{rccccccccccc}\Phi\left[\mathrm{K} \mathrm{min}^{-1}\right] & 1 & 1 \mathrm{~A} & 2 & 3 & 4 & 5 & 6 & 7 & 8 & w & w_{\mathrm{TGA}} \\ 1 & 0.008 & 0.007 & 0.027 & 0.054 & 0.033 & 0.000 & 0.036 & 0.009 & 0.027 & 0.201 & 0.195 \\ 5 & 0.008 & 0.010 & 0.030 & 0.054 & 0.035 & 0.000 & 0.046 & 0.002 & 0.026 & 0.210 & 0.206 \\ 10 & 0.007 & 0.009 & 0.027 & 0.041 & 0.045 & 0.001 & 0.037 & 0.008 & 0.027 & 0.202 & 0.196 \\ 15 & 0.008 & 0.011 & 0.026 & 0.054 & 0.034 & 0.003 & 0.038 & 0.010 & 0.022 & 0.203 & 0.199 \\ 20 & 0.008 & 0.011 & 0.024 & 0.053 & 0.034 & 0.003 & 0.036 & 0.010 & 0.022 & 0.200 & 0.197 \\ 50 & 0.008 & 0.011 & 0.023 & 0.049 & 0.040 & 0.005 & 0.031 & 0.014 & 0.020 & 0.201 & 0.197\end{array}$

Table 8 . Values of $B_{i}\left[10^{4} \mathrm{~K}\right]$ optimized for average reaction orders and pre-exponential factors.

\begin{tabular}{l|ccccccccc} 
Peak & 1 & $1 \mathrm{~A}$ & 2 & 3 & 4 & 5 & 6 & 7 & 8 \\
\hline Kissinger & 2.25 & 2.04 & 1.88 & 1.61 & 1.83 & 4.49 & 2.98 & 3.17 & 2.60 \\
Fit to all data & 2.25 & 2.04 & 1.87 & 1.61 & 1.83 & 4.52 & 2.98 & 3.17 & 2.59 \\
Average of separate fits & 2.25 & 2.04 & 1.88 & 1.61 & 1.83 & 4.50 & 2.99 & 3.17 & 2.59 \\
StDev & 0.01 & 0.01 & 0.01 & 0.00 & 0.01 & 0.02 & 0.01 & 0.03 & 0.03
\end{tabular}




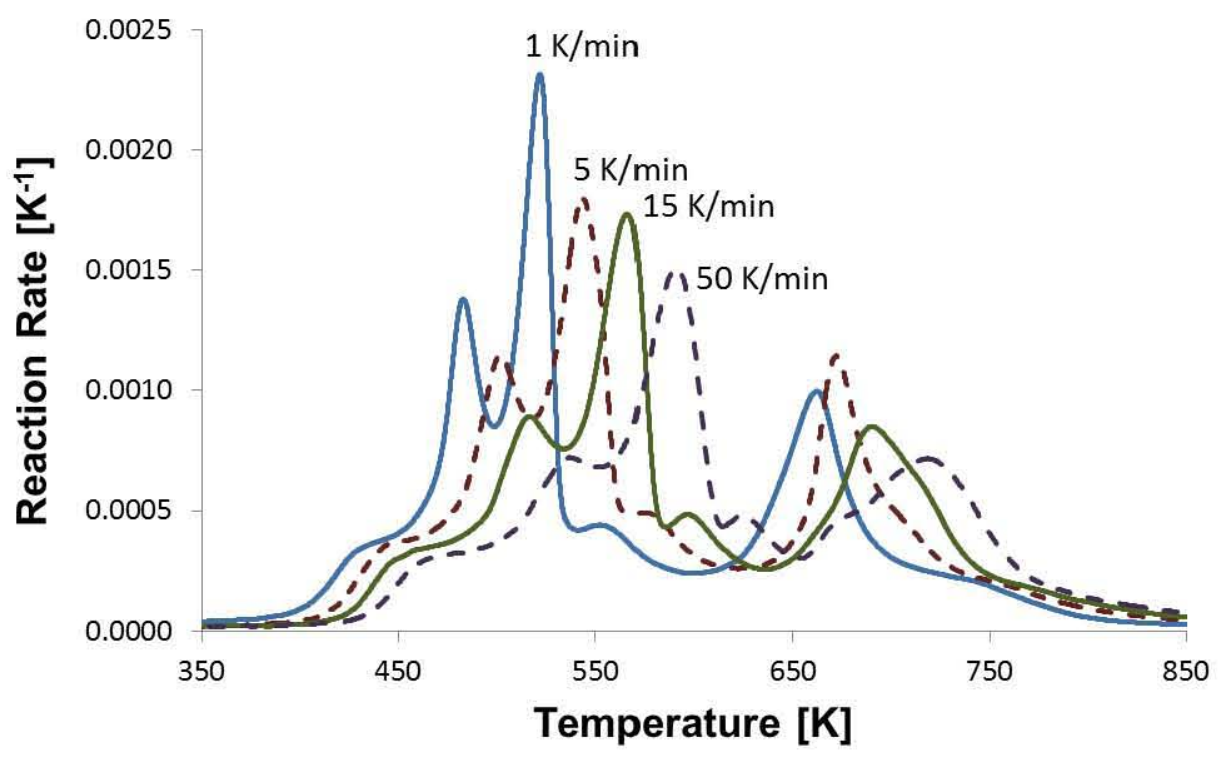

Fig. 1. 


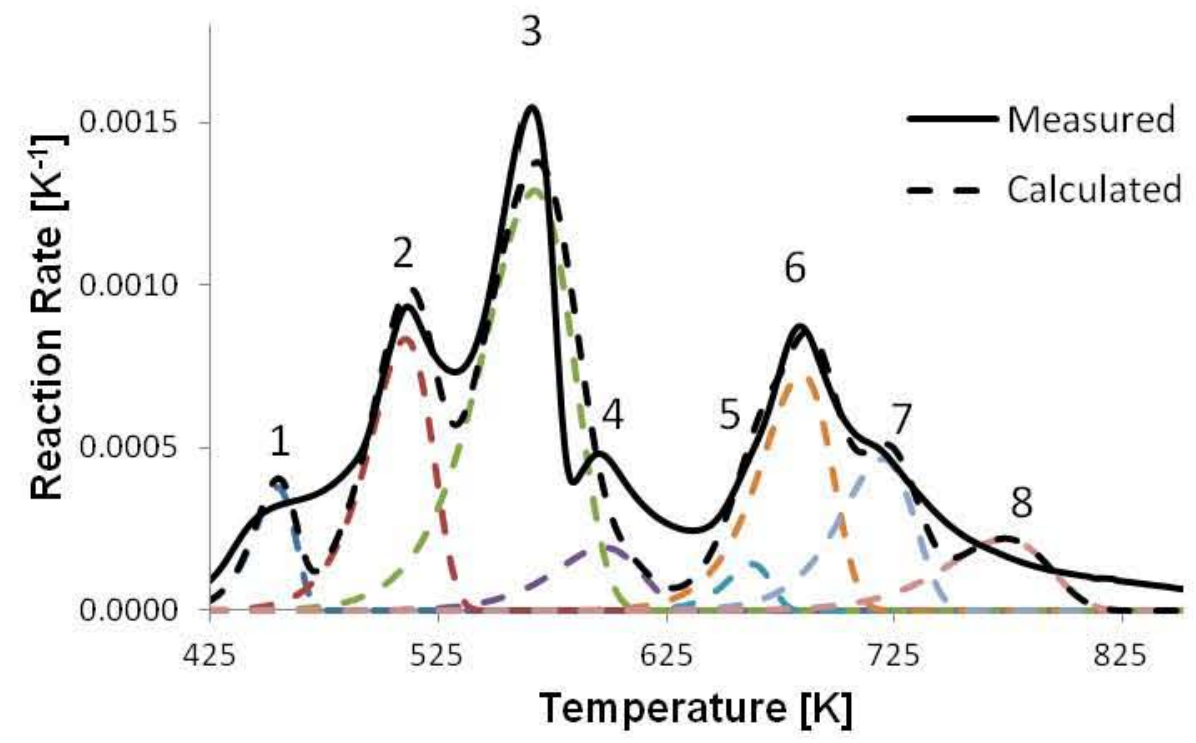

Fig. 2. 


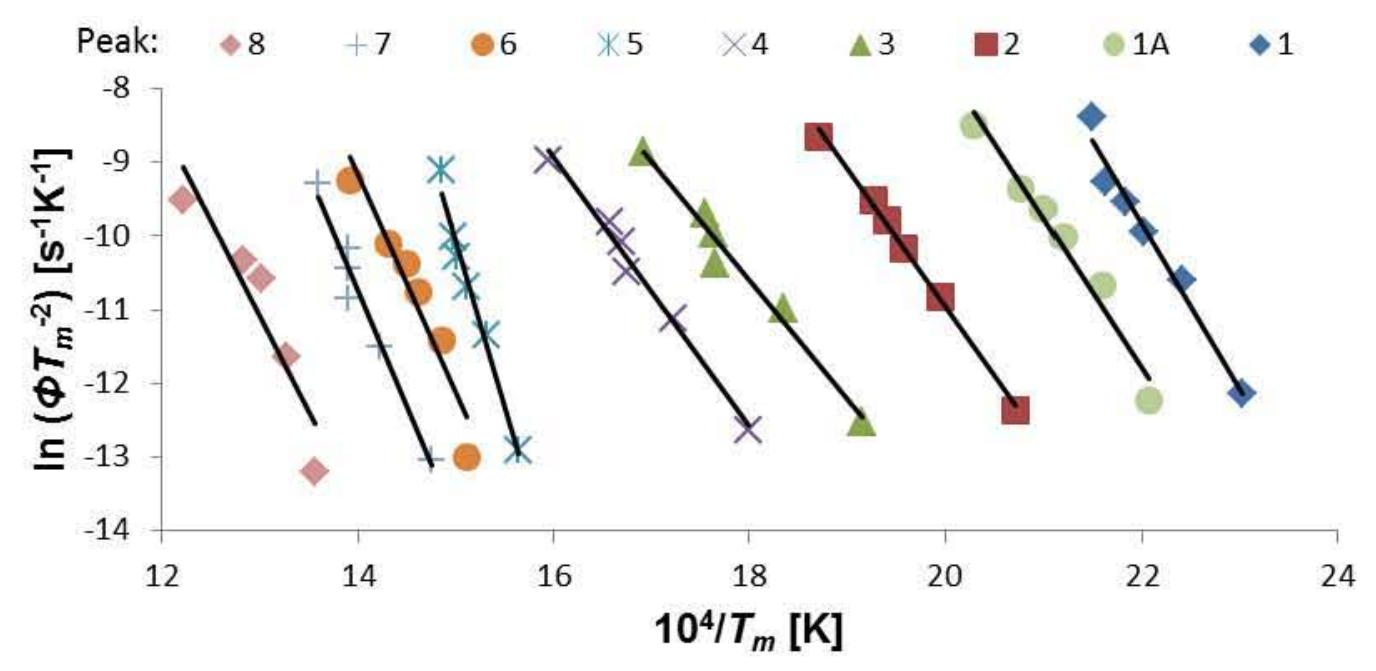

Fig. 3. 


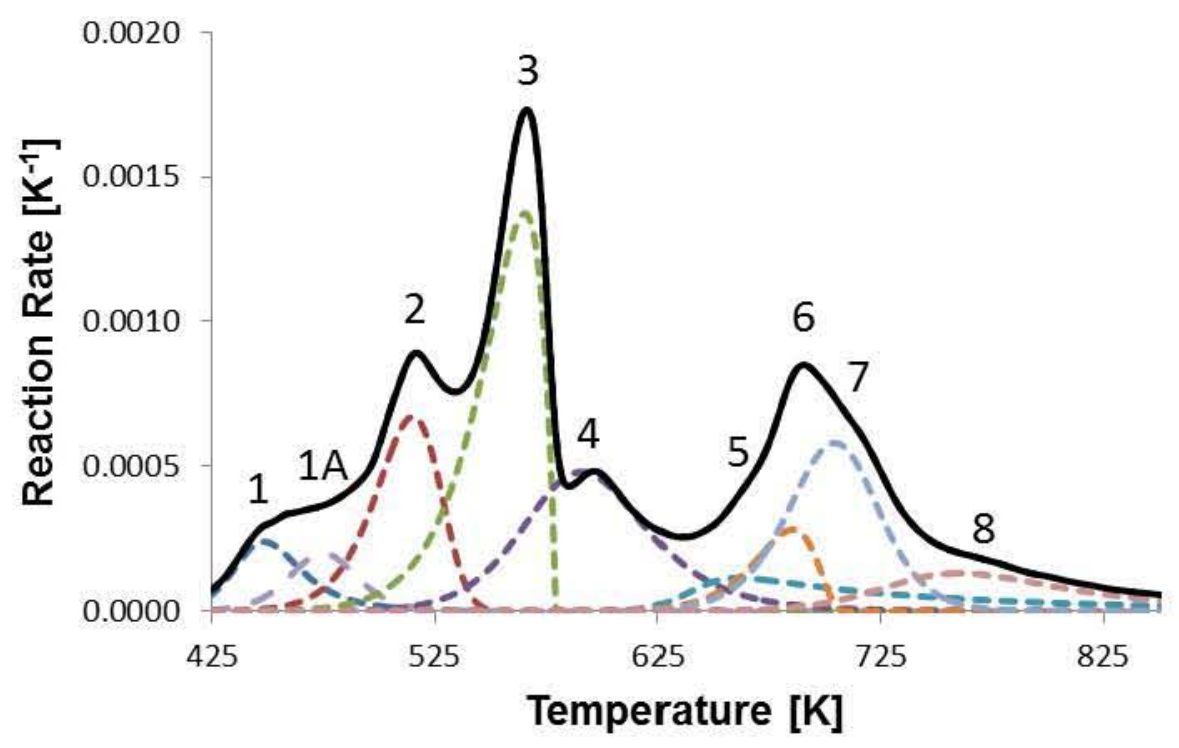

Fig. 4. 


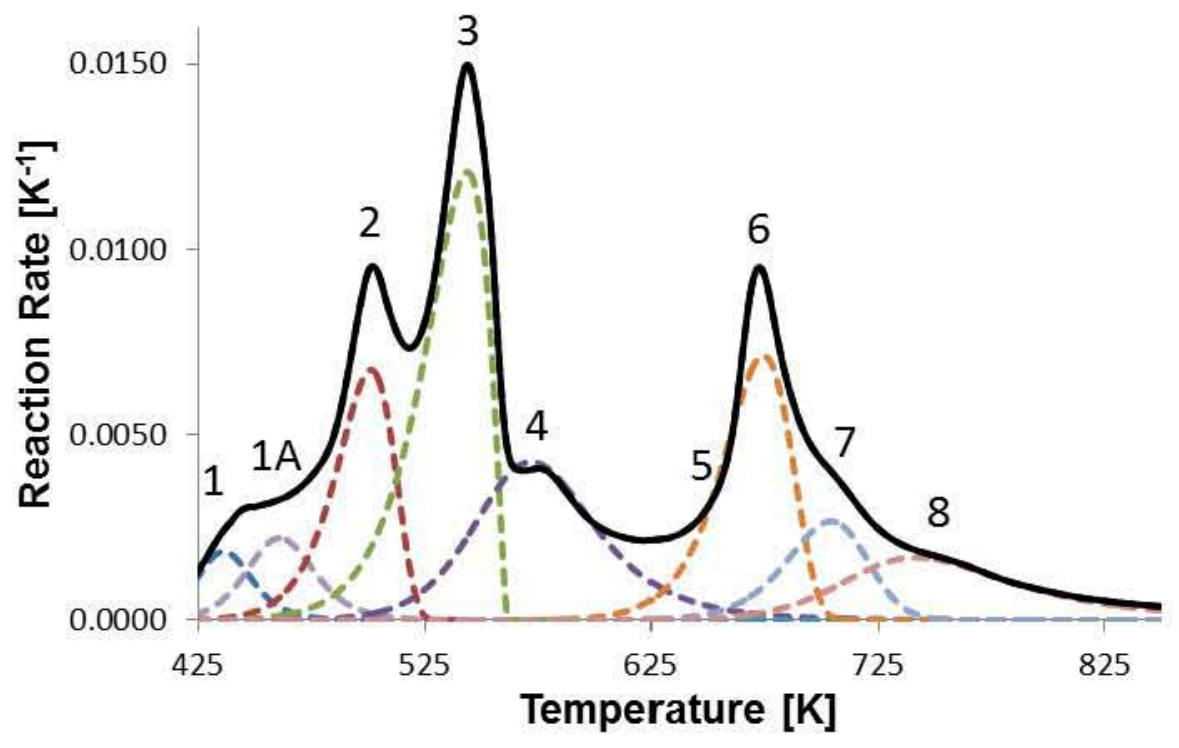

Fig. 5. 

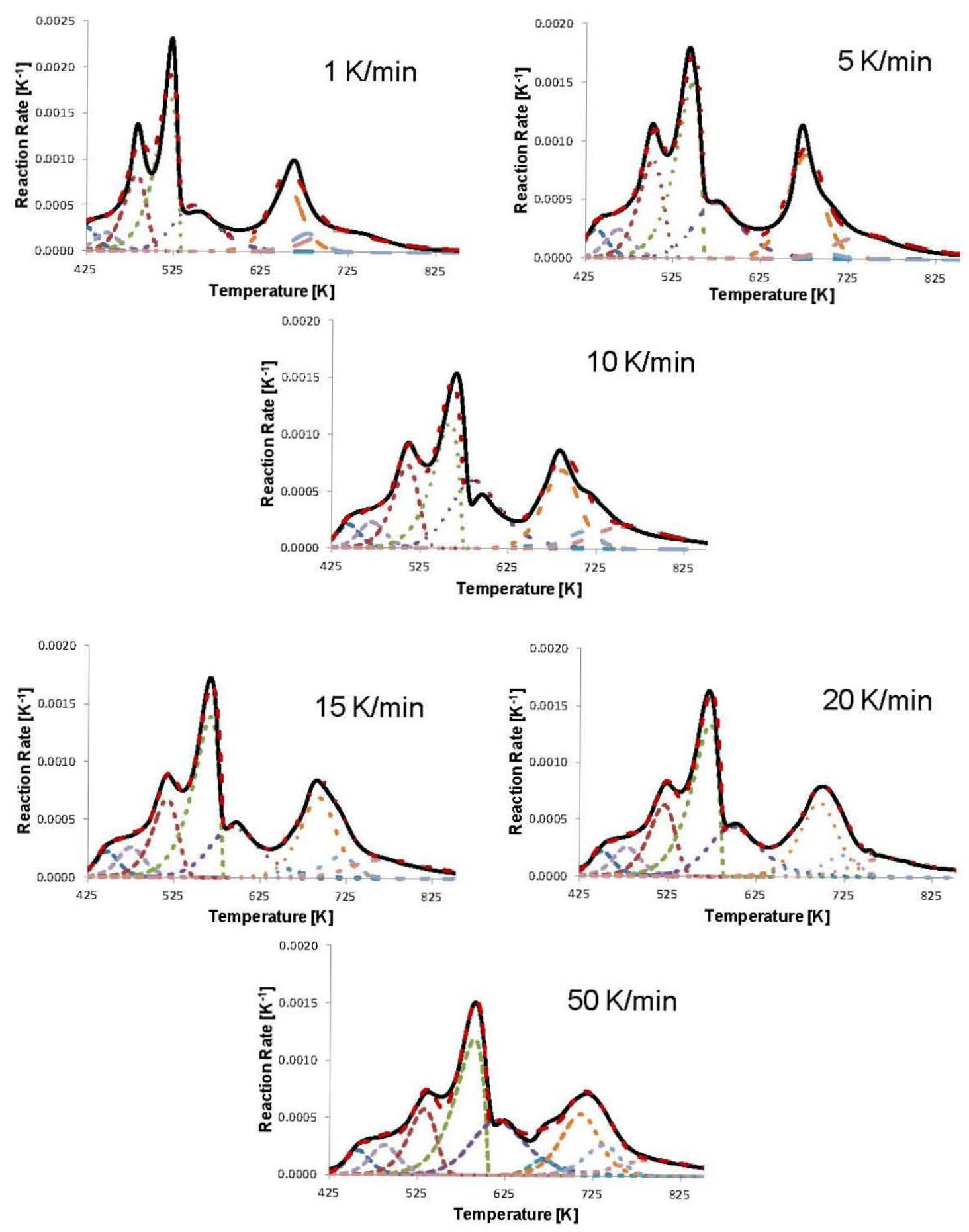

Fig. 6. 


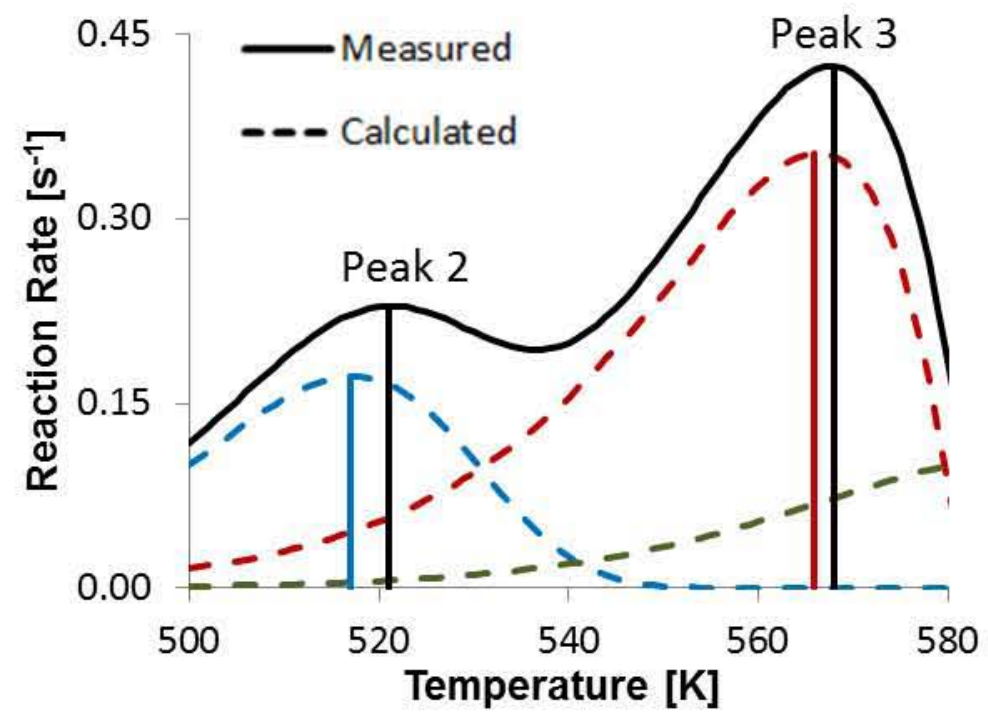

Fig. 7. 


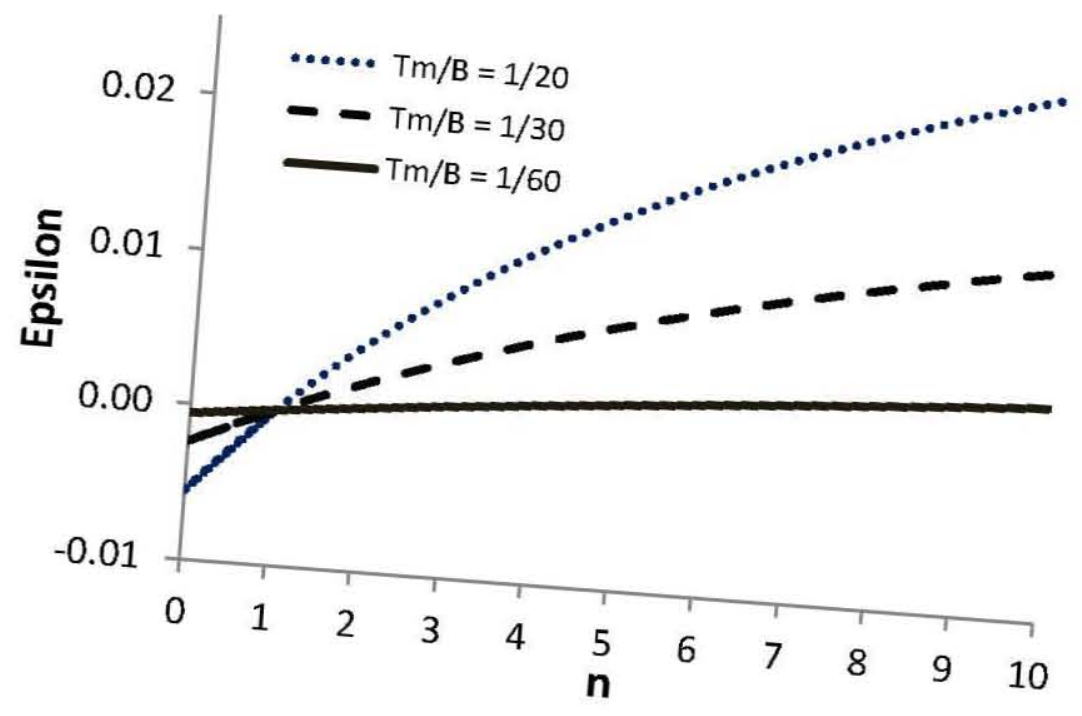

Fig. A1. 


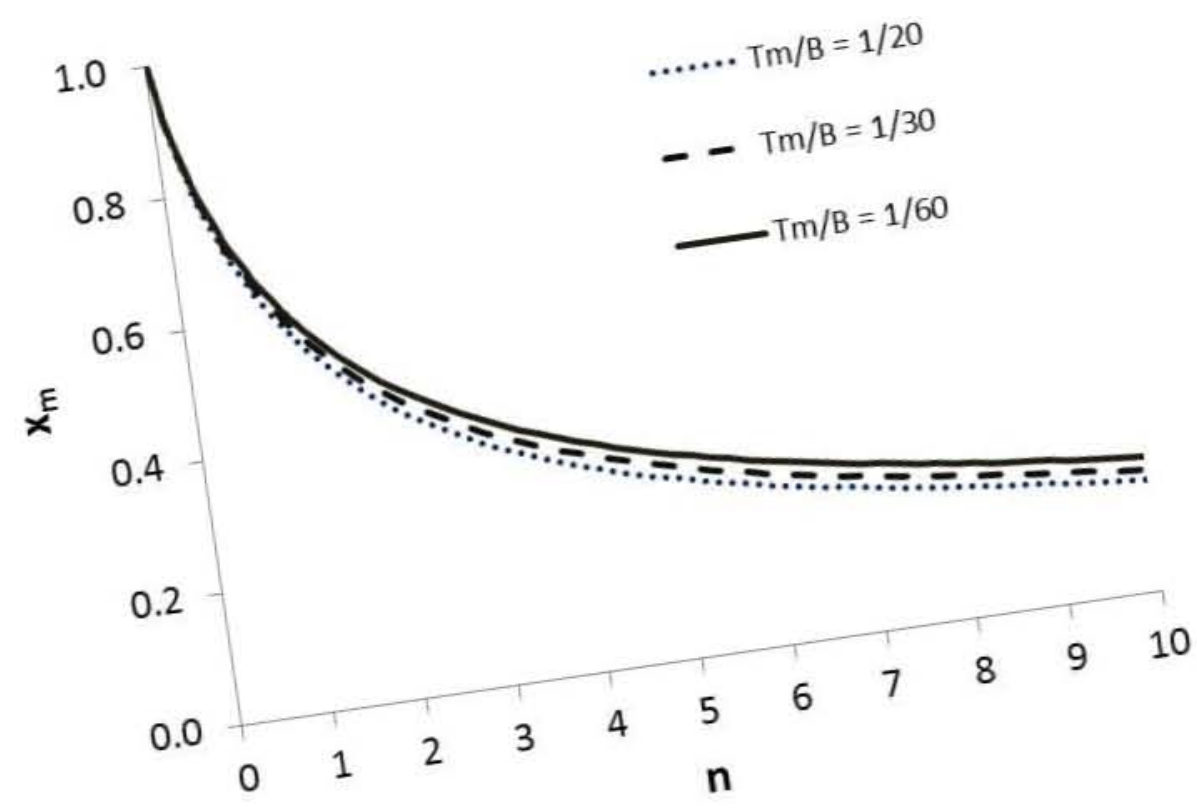

Fig. A2. 

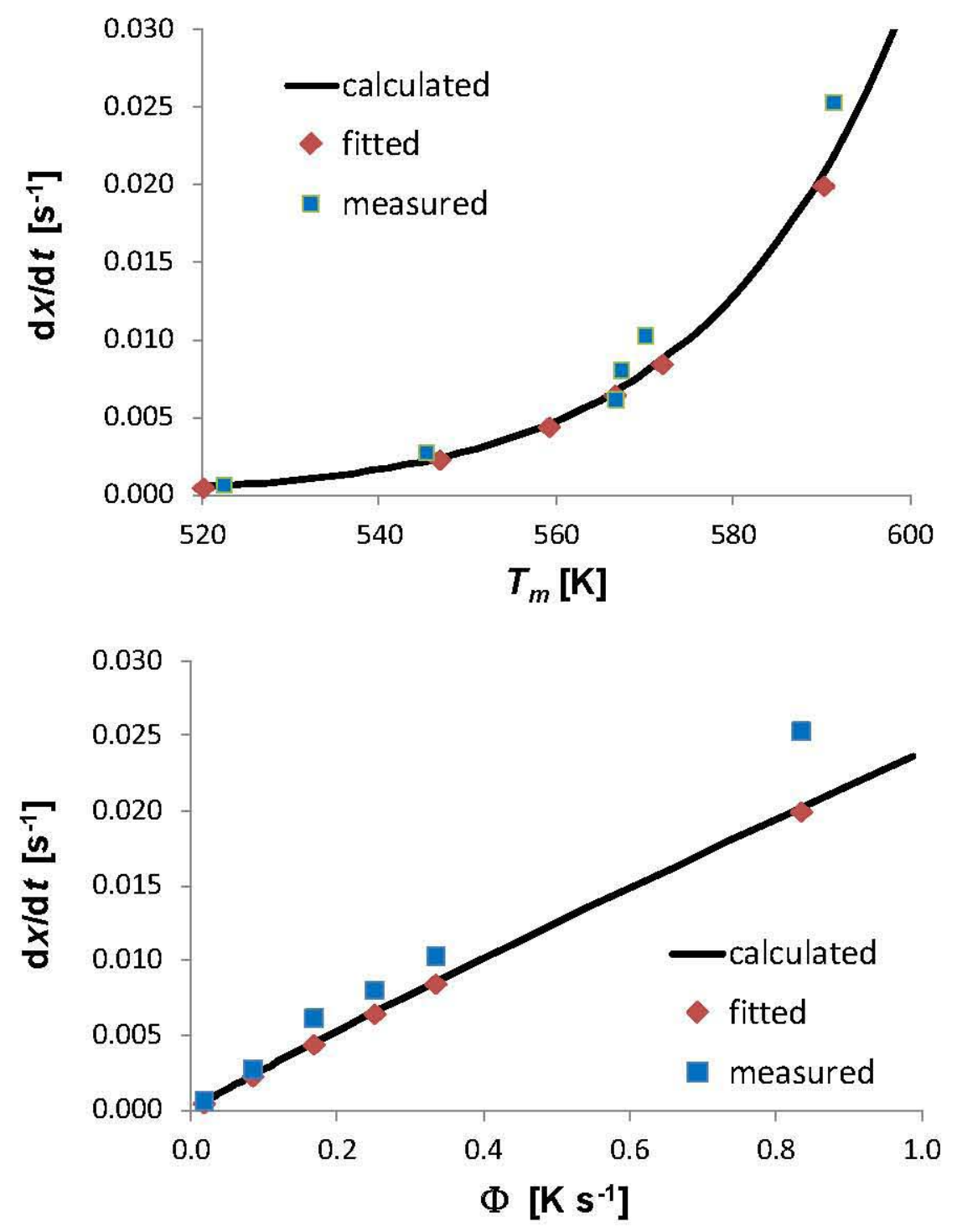

Fig. B1. 


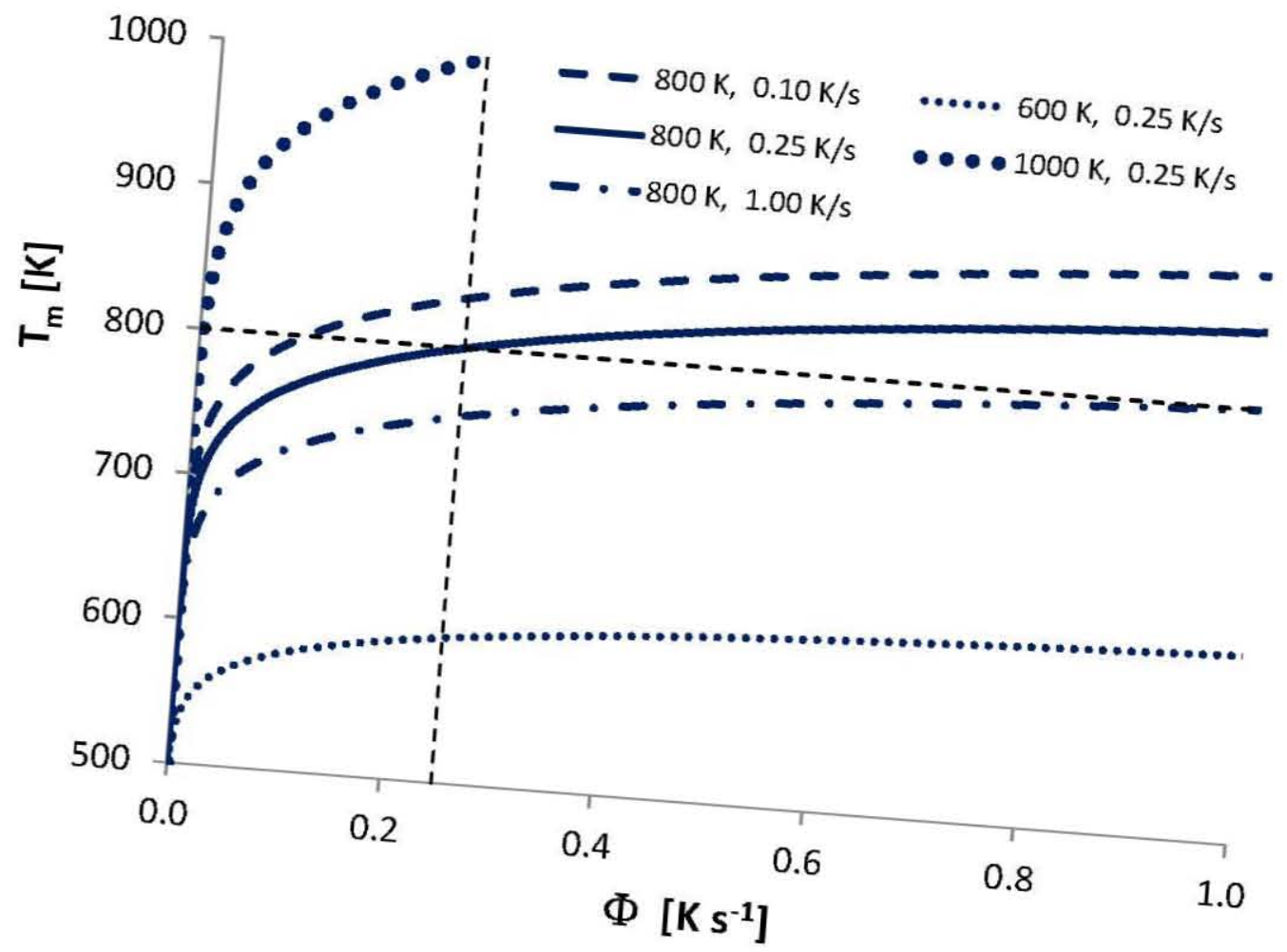

Fig. B2. 